\title{
Ultrasensitive twin-core photonic bandgap fiber refractive index sensor
}

\author{
Yuan, Scott Wu; Town, Graham; Bang, Ole
}

Published in:

Proceedings of the 14th OptoElectronics and Communications Conference

Link to article, DOI:

10.1109/OECC.2009.5219053

Publication date:

2009

Document Version

Publisher's PDF, also known as Version of record

Link back to DTU Orbit

Citation (APA):

Yuan, S. W., Town, G., \& Bang, O. (2009). Ultrasensitive twin-core photonic bandgap fiber refractive index sensor. In Proceedings of the 14th OptoElectronics and Communications Conference: OECC 2009 (pp. 1-2). IEEE. https://doi.org/10.1109/OECC.2009.5219053

\section{General rights}

Copyright and moral rights for the publications made accessible in the public portal are retained by the authors and/or other copyright owners and it is a condition of accessing publications that users recognise and abide by the legal requirements associated with these rights.

- Users may download and print one copy of any publication from the public portal for the purpose of private study or research.

- You may not further distribute the material or use it for any profit-making activity or commercial gain

- You may freely distribute the URL identifying the publication in the public portal

If you believe that this document breaches copyright please contact us providing details, and we will remove access to the work immediately and investigate your claim. 


\title{
Ultrasensitive Twin-core Photonic Bandgap Fiber Refractive Index Sensor
}

\author{
Wu Yuan ${ }^{1, *}$, Graham E. Town ${ }^{2}$, Ole Bang ${ }^{1}$ \\ ${ }^{1}$ DTU Fotonik, Dept. of Photonics Engineering, Technical University of Denmark, \\ DK-2800 Kgs. Lyngby, Denmark \\ ${ }^{2}$ Department of Electronics, Macquarie University, NSW 2109, Australia \\ *Phone: + (45) 4525 3979, Fax: + (45) 4593 6581, Email: wyuan@fotonik.dtu.dk
}

\begin{abstract}
We propose a microfluidic refractive index sensor based on new polymer twin-core photonic bandgap fiber (PBGF). The sensor can achieve ultrahigh detection limit, i.e. $>1.4 \times 10^{-7} \mathrm{RIU}$ refractive index unit (RIU), by measuring the coupling wavelength shift.

\section{Introduction}

There is a growing interest of research in fiber optic refractive index sensors and biosensors using the principle of evanescent wave sensing. Most of the efforts have been concentrated on developing a so-called labelfree fiber sensor to detect tiny refractive index change. In this context, photonic cystal fibers (PCFs) have received considerable attention recently since PCF have the advantage to infiltrate analyte into the air holes and thereby create a strong light-matter interaction between the probing electromagnetic field and ambient analyte [1, 2]. However, current label free fiber sensors, either based on conventional single mode fiber or PCFs, can not compete with mainstream label free optical sensors, e.g. surface Plasmon resonance (SPR) sensors. The practical detection limit of fiber sensor is bottlenecked by $10^{-5}$ RIU $[1,2,3]$.
\end{abstract}

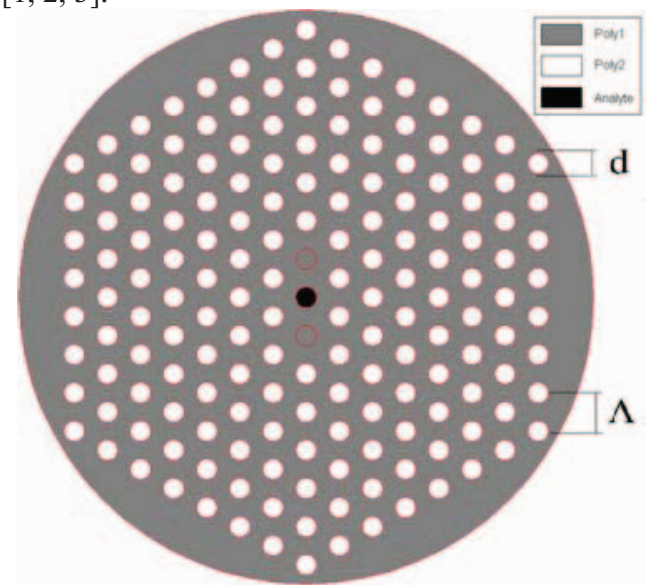

Figure 1, polymer PBGFS fabricated with CYTOP and TOPAS. Meanwhile, we witness that, due to the flexibility of design and ease of fabrication, multi-core PCFs, especially the multi-core PBGFs, have attracted increasing interests for potential applications of optical communication and sensors $[4,5,6]$. Theoretical and experimental studies of multi-core PBGFs have shown that such fibers have some remarkable coupling properties, e.g. the decoupling and extremes of coupling length $[4,5]$. Here we describe a novel PBGFs with two solid cores and one single microfluidic analyte channel between two cores. As shown in figure 1, this fiber is proposed to be fabricated with two different biocompatible polymers, i.e. Poly1 and Poly2. Poly1 will be lower refractive index background material (1.34 RIU), Poly2 works as high index rod (1.53 RIU) and is placed in a periodic triangular structure, which is characterized by the pitch $(\Lambda)$ and diameter of rod $(d)$. The twin-core PBGFS forms a directional coupler and have broad transmission windows or bandgaps (BG) delimited by the cut-off wavelengths of the modes of individual high index rod, which is shown in figure 2.

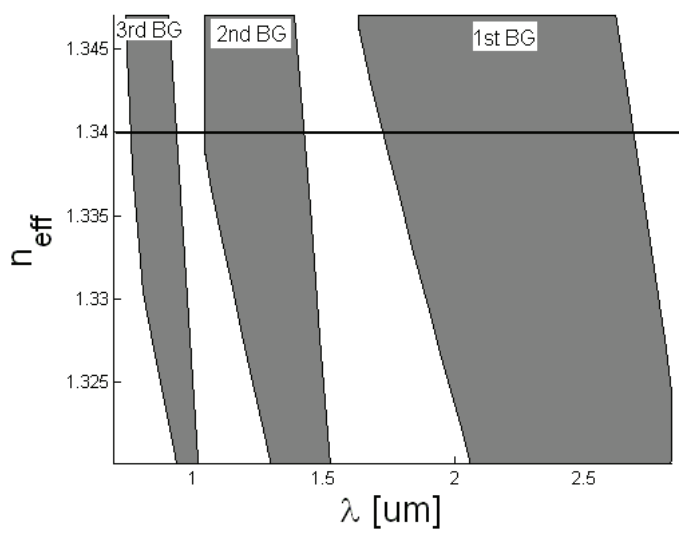

Figure 2, Bandgaps of proposed polymer PGBF with $\Lambda=3.2 \mathrm{um}$ and $\mathrm{d}=1.7 \mathrm{um}$, refractive index of cores is illuminated with solid black line. Principle and modelling

In a twin-core PBGF with two identical single-mode cores, the modes of the individual cores interact via their evanescent fields and form a pair of supermodes, i.e. symmetric (even) supermode and antisymmetric (odd) supermode. The phase mismatching between two supermodes will decide the beating length or coupling length $\left(\boldsymbol{L}_{c}\right)$ of one wavelength totally coupling from one core to the other core:

$$
L_{c}=\pi / k\left|n_{\text {odd }}-n_{\text {even }}\right|
$$

Where $n_{\text {even }}$ and $n_{\text {odd }}$ are the corresponding effective indices of even and odd supermodes respectively, $\mathrm{k}=2 \pi / \lambda$ and $\lambda$ is the free space wavelength.

In conventional twin-core indexing guiding fibers, $\boldsymbol{L}_{c}$ increases monotonically with frequency and depends primarily on cores' separation [6]. So theoretically twincore fibers with constant length allow for label free refractive index sensing by tracking the shift of coupling wavelength, which is caused by the change of $\Delta \mathrm{n}_{\text {eff }}$ 
$\left(\Delta \mathrm{n}_{\text {eff }}=\mathrm{n}_{\text {odd }}-\mathrm{n}_{\text {even }}\right)$ and in turn the real refractive index change $\Delta \mathrm{n}$.

As demonstrated in figure 3.a and 3.b, the core-guided supermodes have a presence in the high-index rods in PBGF, so the filed distributions in the rods play a key

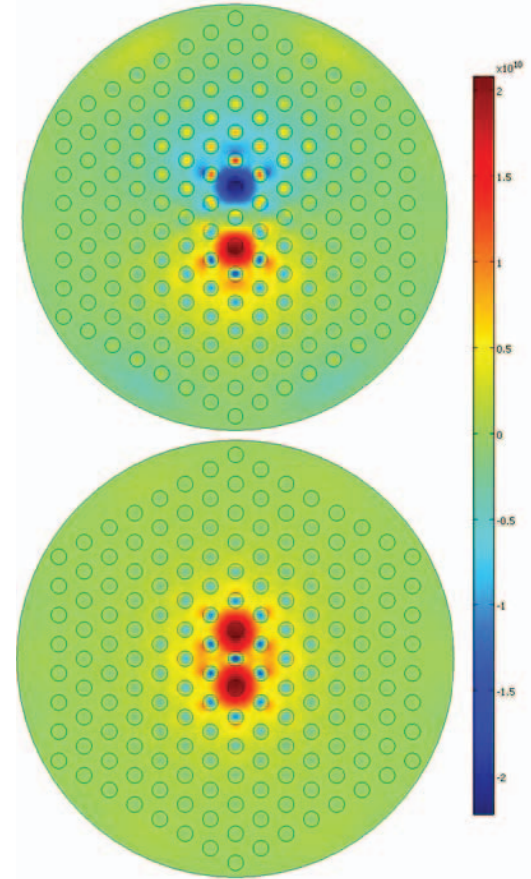

Figure 3, the Ex field distribution of odd and even supermodes in proposed PBGFS.

role in the coupling properties of twin-core PBGFS. The rod directly between the cores, i.e. the microfluidic analyte channel in our fiber, is particularly important because this is where even and odd supermodes are most clearly different. Figure 4 shows that within the $2^{\text {nd }} B G$, when the refractive index change from 1.400RIU to 1.401RIU $(\Delta \mathrm{n}=0.001 \mathrm{RIU})$ inside this channel, the $\Delta \mathrm{n}_{\mathrm{eff}}$ curve (black solid line) is shifted upwards (red solid line) and corresponding $\boldsymbol{L}_{c}$ curve (black solid line) is shifted downwards (red solid line). The key feature in figure 4 is the flat part of both $\Delta \mathrm{n}_{\mathrm{eff}}$ and $\boldsymbol{L}_{c}$ curves with the variation of wavelength $\lambda$. The minimal extreme of coupling length reflects a maximal coupling between two core modes, thus corresponds to the maximal $\Delta \mathrm{n}_{\text {eff }}$.

If the length of fiber is $335 \mathrm{um}$, i.e. the minimal extreme of $\boldsymbol{L}_{c}$, the $\Delta \mathrm{n}$ of analyte leads to the big shift of coupling wavelength, i.e. $70 \mathrm{~nm}$. We assume the wavelength resolution of instrument to be $0.01 \mathrm{~nm}$, our refractive index sensor can offer a detection limit about $1.4 \times 10^{-7}$ RIU, and this is not yet the highest theoretical detection limit that can be achieved with our PBGF.

\section{Discussions and Conclusions}

Comparing with twin-core index guiding PCF, a remarkable feature of PBGF is that $n_{\text {odd }}$ is bigger than $\mathrm{n}_{\text {even }}$ in some BGs, i.e. $2^{\text {nd }} \mathrm{BG}$ in our case, which is never seen in both index guiding PCFs and conventional twincore fibers [6].

As shown in figure 3, twin-core PBGF has a set of highindex cladding modes that are localized, or have a significant part of their weight, in the high-index rods. In the index-guiding case, all high-index cladding states are expelled from the holes [6]. The fact that the coupling lengths in the PBGF are much smaller than in the indexguiding coupler suggests that the cladding states in the high-index areas mediate interaction between the core modes through off-resonant coupling. This maybe suggests another possible way to enhance the detection limit is to take advantage of all ambient rods of two cores as analyte channels. Short coupling length will result in a significant advantage for application of biosensor, where the necessary analyte volume for sensing will be greatly reduced.
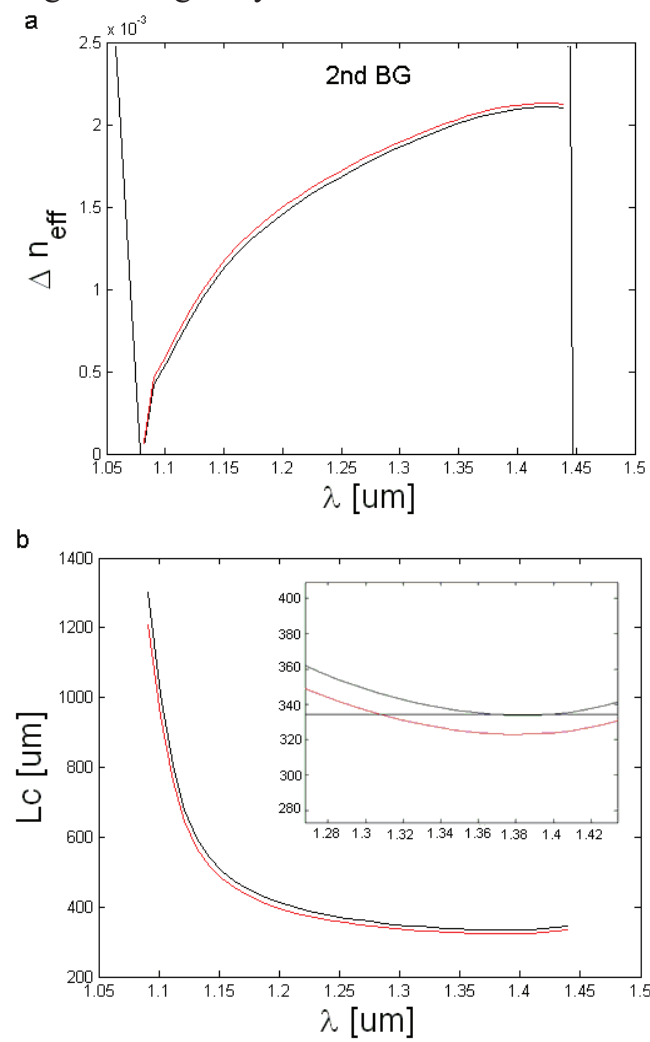

Figure 4 , (a) variation of $\Delta n_{\text {eff }}$ within $2^{\text {nd }} B G$ induced by $\Delta n$ of analyte, and (b) corresponding coupling length change, inset is amplified flat part of coupling length curve (Black solid line---1.400RIU,Red solid line---1.401RIU).

The detection limit of proposed polymer twin-core PBGF strongly depends on the photonic crystal structure, thus appropriate choice of the pitch $(\Lambda)$ and diameter of rod (d) can optimize the performance of proposed refractive index sensor further. Furthermore, the sensitivity of our sensor scales with length.

\section{References}

1. L. Rindorf and O. Bang, J. Opt. Soc. Am. B (2008) p. 310-324.

2. L. Rindorf and O. Bang, Opt. Lett. (2008) p. 563-565.

3. D. K. C. Wu, B. T. Kuhlmey, and B. J. Eggleton, Opt. Lett. (2009) p.322-324.

4. Z. Wang, T. Taru, T. A. Birks, J. C. Knight, Opt. Express (2007) p. 4795-4803.

5. J. Lægsgaard, Opt. Lett. (2005) p.3281-3283.

6. J. Lægsgaard, O. Bang, and A. Bjarklev, Opt. Lett. (2004) p.2473-2475. 